\title{
Molecular alteration in the Gap Junction Beta 2 (GJB2) gene associated with non-syndromic sensorineural hearing impairment
}

\author{
Smita Hegde ${ }^{1,3}$, Rajat Hegde ${ }^{2,3}$, Suyamindra S Kulkarni ${ }^{3}$, Kusal K Das ${ }^{2}$, Pramod B Gai ${ }^{3, *}$, \\ Rudregouda Bulgouda ${ }^{1}$ \\ ${ }^{1}$ Human genetics laboratory, Department of Anatomy, Shri B. M. Patil Medical College, Hospital and Research centre, BLDE (Deemed to be \\ University), Vijayapura, India; \\ ${ }^{2}$ Laboratory vascular physiology and medicine, Department of Physiology, Shri B. M. Patil Medical College, Hospital and Research centre, \\ BLDE (Deemed to be University), Vijayapura, India; \\ ${ }^{3}$ Karnataka Institute for DNA Research (KIDNAR), Dharwad, India.
}

SUMMARY Non-syndromic sensory neural hearing defect is one of the genetic diseases inherited from parents to offerings. The autosomal recessive form affects a large population worldwide and has become a major concern in the social and professional lives of many people. There are many factors and genes which are involved in hearing loss but the Gap Junction Beta 2 (GJB2) gene which encodes the connexin 26 protein, is a major cause of non-syndromic recessive deafness (NSRD). This study aims to record and analyze GJB2 gene mutations in the hearing-impaired population of North Karnataka, India. In this study, we included 368 congenitally hearing-impaired children from North Karnataka, India, under 18 years of age. After thorough clinical examinations, patient's history and proper audiological results, peripheral blood samples were collected and subjected to genetic analysis. We recorded that $54.8 \%$ of the NSRD cases have an autosomal recessive mutation in the coding region of the GJB2 gene. The frequency of W24X (25\%) mutation was found to be high in the present study population. From this study we can suggest that, identifying this mutation in newborns definitely helps in the early diagnosis of hearing loss.

Keywords autosomal recessive, non-syndromic recessive deafness, connexin 26, deaf mute, India

\section{Introduction}

Hearing loss or deafness is one of the most common global health issues, where patients who lose the ability to hear may be permanent or oscillating. Deafness is also one of the most prevalent inherited sensory disorders in most parts of the world (1). Approximately 1 in 1,000 new-borns suffer from severe to profound hearing loss. In that $>50 \%$ of cases are due to genetic factors (2). Environmental factors also play a major role in inducing deafness. For example, congenital hyperbilirubinemia, ototoxic medication, neonatal hypoxia, viral infections, and meningitis are some non-genetic factors inducing congenital hearing loss (3). $70-80 \%$ of non-syndromic genetic hearing loss is inherited as an autosomal recessive form (DFNB), whereas autosomal dominant forms (DFNA) make up about 10-20\% (Dominant forms are designated with the suffix ' $\mathrm{A}$ ' and recessive forms with suffix 'B') and the $\mathrm{X}$ linked form (DFN) accounts for about $1-2 \%$ (4). DFNB1 gene locus, which is responsible for non-syndromic deafness is present on the $13 \mathrm{q} 11$ chromosome locus is most prevalent all over the world (5). 13q11 chromosome region includes two major genes viz, connexin 26(GJB2) and connexin $30(G J B 6)$, which show high involvement in deafness. Connexin 26 (GJB2) is the major gene responsible for hearing loss all over the world (5). Epidemiological data evaluation of deafness in different populations of the world also revealed that connexin 26 is the single most cause of inherited deafness (5). Syndromic forms of deafness which account for more than 500 types can be easily diagnosed whereas non-syndromic forms of deafness can only be resolved by genetic analysis ( 6 ). The genetic cause of deafness is heterogenous. Until now, more than 100 mapped loci associated with nonsyndromic hearing loss have been described (https:// hereditaryhearingloss.org/). According to the Human Gene Mutation Database (HGMD) the total number of genes involved in hearing loss (HL) is 316 , in that 105 genes are related to NSRD. 444 mutations are recorded worldwide specific to the GJB2 gene (Disease causing mutations-355, non-syndromic HL mutations-51) (http:// 
www.hgmd.cf.ac.uk). W24X mutation in the GJB2 gene is known to be common in the Indian population. Still, the full spectrum of mutation of this gene occurring in India is not known (7).

Connexin is a membrane protein with four transmembrane domains, which are called connexins. These connexin proteins form a hexamer by combining six molecules, called a connexon. A gap junction is formed by the hexamers forming a cell-to-cell channel to the adjacent cells. Small molecules and ions move through this junction to the adjacent cells. Various forms of connexin proteins form different types of hexamers that determine the permeability of different molecules or ions through them $(8)$.

\section{Materials and Methods}

\subsection{Subjects}

After screening 613 bilateral sensory neural congenital hearing loss children under 18 years of age (median age 12), a total of 368 children $\left(n_{\text {male }}=235, n_{\text {female }}=\right.$ 133) were considered for the study. Children belonging to unrelated families, and having a family history of hearing loss or born to consanguineous marriages were included in the study. Children who had a syndromic hearing loss or were affected by environmental factors and above the age of 18 were excluded from the study. To confirm that the hearing loss occurred because of non-genetic causes (viral and bacterial infections, intake of ototoxic drug during pregnancy, and premature birth), a detailed clinical history and data were collected from each family. After proper physical examination pure tone audiometry $(250$ to $8,000 \mathrm{~Hz})$ was obtained from each child. Clinical samples were collected after obtaining written informed consent from each child. Ethical approval for the study was obtained from the Institutional Ethical Committee of, Shri B. M. Patil Medical College, hospital \& research centre, BLDE (Deemed to be University), Vijayapura (Ref noBLDE(DU)/ IEC/335/2018-19).

\subsection{Mutation Analysis}

DNA was isolated from peripheral blood using DNeasy blood and tissue kit (QIAGEN, Germany) according to the standard procedures. This was followed by the polymerase chain reaction (New England Biolab, USA). GJB2 gene (NG_008358) was amplified using specific primers and to check for the proper amplification, PCR products were analyzed by agarose gel electrophoresis. Purified PCR products of the GJB2 gene were sequenced using forward primer and big dye terminator cycle sequencing kit V3.1 (Applied biosystem, USA) using an ABI 3500 Sanger sequencer. A comparison of the GJB2 reference sequence to the individual DNA sequence was made to determine the GJB2 sequence variation.

\subsection{Bioinformatics analysis}

Pathogenic effects of missense variants were predicted using the following Bioinformatics tools, Protein variation effect analyzer (PROVEN) (http://provean.jcvi. org/index.php), Protein Analysis Through Evolutionary Relationships (PANTHER) (http://www.pantherdb. org) SNAP2 (https://www.rostlab.org/services/snap), Polymorphism Phenotyping2 (PolyPhen-2) (http:// genetics.bwh.harvard.edu/pph2), Predictor of human Deleterious Single Nucleotide Polymorphisms (PhDSNP) (https://snps.biofold.org/phd-snp/phd-snp.html), SNPs \& GO (https://snps.biofold.org/snps-and-go/snpsand-go.html) and Deafness Variation Database (DVD) (https://deafnessvariationdatabase.org/gene/GJB2). These Bioinformatic tools were used to predict the pathogenic effects of the variant on the functions of the proteins (9).

Multiple sequence alignment analyses for connexin 26 protein were performed to find the sequence homology from a common ancestor, which also revealed whether they descended from the same/common ancestor (10). Uniport accession numbers from different species were used for the analysis as follows- Xenla Q7ZYG3, Mouse Q009777, Rat P21994, Sheep P46691, Macmu Q8MIT8, Human P29033, Corgo Q8MHW5, Canlf J9NXR. Homology modelling of the mutated protein was predicted using a Swiss-model server and predicted protein model was visualized, and analyzed on a UCSF chimera program.

\section{Results}

In this study, we have screened 613 NSRD children from the North Karnataka population. We have included 368 unrelated children with hearing loss $\left(n_{\text {male }}=235\right.$, $\left.n_{\text {female }}=133\right)$ out of that $16.8 \%(62 / 368)$ children had a family history of deafness. Frequency of consanguineous marriage was $42.1 \%(115 / 368)$ in our study. We recorded 18 mutations in exonic and intronic regions of the GJB2 gene. W24X, and W77X variants were the common mutations identified in this study. A $\mathrm{G}>\mathrm{A}$ transition at c.71 results in a stop codon at p.24 (W24X) of connexin 26 that produces a truncated protein which is one-tenth the length of the wild type protein and a $\mathrm{G}>\mathrm{A}$ transition at c. 231 results in a stop codon at p.77 (W77X) of connexin 26 protein that also produces truncated protein. Both these premature stop codons result in complete loss of the GJB2 gene function. W24X (25\%) is one of the common mutations observed in the study cohort. 86 (23.3\%) deaf children were homozygous and $6(1.6 \%)$ deaf children were heterozygous for this mutation and the W77X mutation was also found to be homozygous (Figure 1).

In our study, we also recorded 3 missense mutations, namely R127H, V153I, and I33T. The frequency of $\mathrm{R} 127 \mathrm{H}$ (14.9\%) mutation among deaf children was 


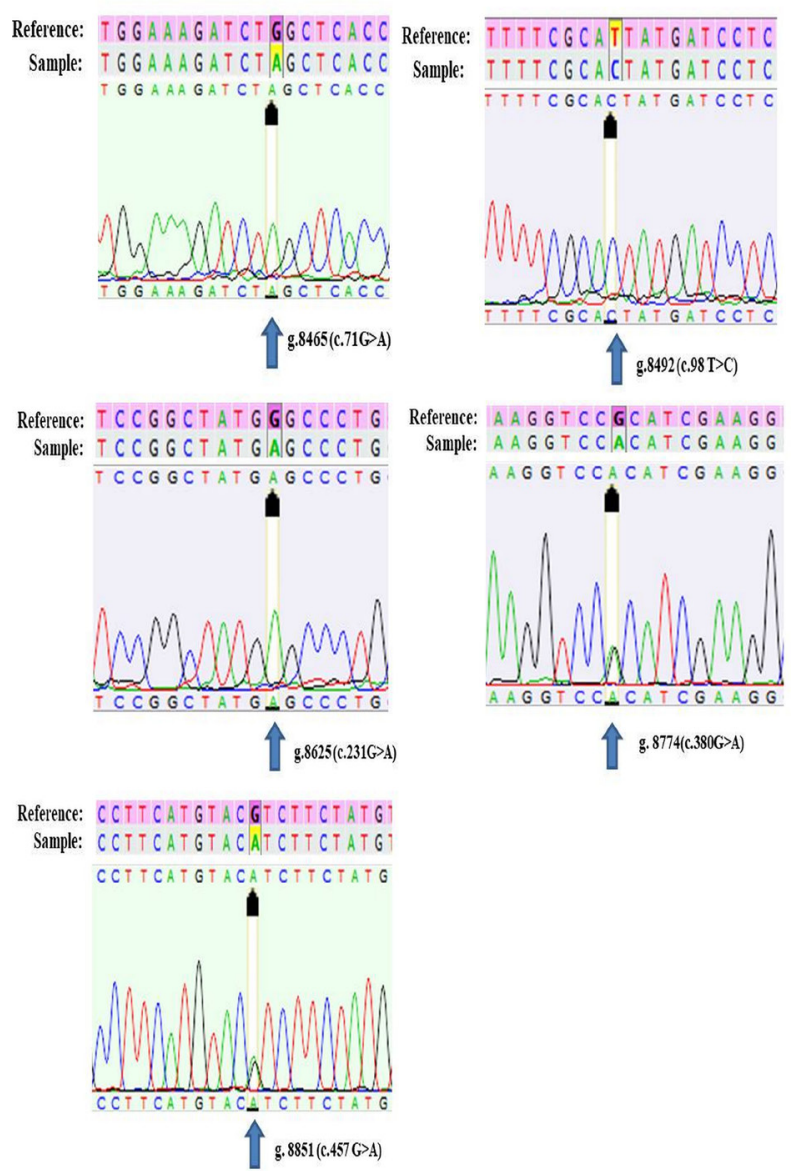

Figure 1. Sequence electropherograms of mutations identified in the present study. W24X (c.71G>A), I33T (c.98T >C), and W77X (c. $231 \mathrm{G}>\mathrm{A})$ mutations were recorded as homozygous. Whereas $\mathrm{R} 127 \mathrm{H}$ (c.380G $>\mathrm{A}$ ) and V153I (c.457G $>\mathrm{A}$ ) mutations recorded as heterozygous. high as compared to the other two identified missense mutations. Four 31-UTR variants were identified (c.84T $>$ C, c. $1067 \mathrm{G}>$ T, c. $1277 \mathrm{~T}>\mathrm{C}$, c. $1152 \mathrm{G}>\mathrm{A}$ ) (Table $1)$. There were no novel mutations observed in our study population. In addition to these exonic variants, we have also recorded 9 variants in the intronic region of the GJB2 gene (Table 2), but these variants are unlikely to be causative. The top and middle electropherograms show the homozygous mutations. The position of mutation is indicated by the arrowhead. Heterozygous mutations are in the bottom c.380 G>A and c. $451 \mathrm{G}>\mathrm{A}$ (Figure 1).

Pathogenicity prediction of the I33T mutation showed the damaging/deleterious effect on the functions of connexin 26 protein. V153I mutations showed a neutral effect, but R127H mutation showed a harmful effect by PhD-SNP, SNP \& GO, and SNAP2 (Table 3). DVD database classified these variants, that shows I33T mutation as pathogenic and the other two mutations V153I and R127H as benign (Table 3). Multiple sequence alignment of the connexin 26 protein was analyzed using the Clustal omega. Mutation I33T and $\mathrm{R} 127 \mathrm{H}$ were highly conserved over different species and mutation V153I was semi-conserved (Figure $2)$. The $3 \mathrm{D}$ models for mutated Connexin 26 protein (W24X and W77X) were generated using SWISSMODEL. The superimposed model shows the loss of the majority of the connexin 26 protein sequences from both mutated proteins (Figure 3). Residue W24 and W77 are present in the first transmembrane (S1) domain and second transmembrane (S2) domain of Connexin 26 respectively.

Table 1. List of mutations identified in the coding sequence of $G J B 2$ gene in the present study

\begin{tabular}{|c|c|c|c|c|c|}
\hline Sl. No. & Nucleotide change & AA change & Frequency & Phenotype & Description and type of effect \\
\hline 1 & c. $71 \mathrm{G}>\mathrm{A}$ & W24X & $25 \%$ & Congenital profound hearing loss & Stop Gained \\
\hline 2 & c. $98 \mathrm{~T}>\mathrm{C}$ & $\mathrm{I} 33 \mathrm{~T}$ & $5.2 \%$ & Congenital profound hearing loss & Missense variant \\
\hline 3 & c. $231 \mathrm{G}>\mathrm{A}$ & W77X & $4.8 \%$ & Congenital severe hearing loss & Stop gained \\
\hline 4 & c. $380 \mathrm{G}>\mathrm{A}$ & $\mathrm{R} 127 \mathrm{H}$ & $14.9 \%$ & Congenital severe hearing loss & Missense \\
\hline 5 & c. $451 \mathrm{G}>\mathrm{A}$ & V153I & $4.9 \%$ & Congenital profound hearing loss & Missense \\
\hline 6 & g.9159T $>C$ & ------------- & $100 \%$ & Congenital profound hearing loss & 3'-UTR Variant \\
\hline 7 & g. $10142 \mathrm{G}>\mathrm{T}$ & ------------- & $100 \%$ & Congenital severe hearing loss & 3'-UTR Variant \\
\hline 8 & g. $10352 \mathrm{~T}>\mathrm{C}$ & ----------- & $100 \%$ & Congenital profound hearing loss & 3'-UTR Variant \\
\hline 9 & g. $10227 \mathrm{G}>\mathrm{A}$ & ------------- & $5.1 \%$ & Congenital severe hearing loss & 3'-UTR Variant \\
\hline
\end{tabular}

Table 2. Mutations were identified in the intronic region of the $G J B 2$ gene in the present study

\begin{tabular}{|c|c|c|c|c|}
\hline S1. No. & Nucleotide change & Frequency & Phenotype & Description \& type of effect \\
\hline 1 & g. $5985 \mathrm{C}>\mathrm{T}$ & $90 \%$ & Congenital profound $\mathrm{HI}$ & Regulatory region Variant \\
\hline 2 & g. $6284 \mathrm{~A}>\mathrm{G}$ & $90 \%$ & Severe to profound HI & Regulatory region Variant \\
\hline 3 & g. $6514 \mathrm{G}>\mathrm{A}$ & $14.94 \%$ & Congenital profound $\mathrm{HI}$ & Regulatory region Variant \\
\hline 4 & g. $7170 \mathrm{~A}>\mathrm{G}$ & $100 \%$ & Moderate HI & Regulatory region Variant \\
\hline 5 & g. $7175 \mathrm{G}>\mathrm{A}$ & $25 \%$ & Severe HI & Regulatory region Variant \\
\hline 6 & g. $8151 \mathrm{C}>\mathrm{S}$ & $4.9 \%$ & Severe HI & ------- \\
\hline 7 & g.8207T $>W$ & $14.94 \%$ & Congenital profound $\mathrm{HI}$ & -------- \\
\hline 8 & g. $8332 \mathrm{~T}>\mathrm{G}$ & $30 \%$ & Congenital Severe to profound HI & -------- \\
\hline 9 & g. $7111 \mathrm{G}>\mathrm{R}$ & $14 \%$ & Congenital profound $\mathrm{HI}$ & --------- \\
\hline
\end{tabular}


Table 3. Pathogenicity of the missense variant by insilico tools

\begin{tabular}{|c|c|c|c|c|c|c|c|}
\hline Variants & SNAP2 & PolyPhen 2 & PhD-SNP & SNPS \& GO & DVD \& CADD & PROVEAN & PANTHER \\
\hline I33T & $\begin{array}{l}\text { Effect } \\
\text { Score:55 }\end{array}$ & $\begin{array}{l}\text { Possibly damaging } \\
\text { Score: } 0.792\end{array}$ & $\begin{array}{l}\text { Disease } \\
\text { P: } 0.548\end{array}$ & $\begin{array}{l}\text { Disease } \\
\text { P: } 0.548\end{array}$ & $\begin{array}{l}\text { Pathogenic } \\
25.2\end{array}$ & $\begin{array}{l}\text { Deleterious } \\
\text { Score: }-3.722\end{array}$ & Possibly damaging \\
\hline $\mathrm{R} 127 \mathrm{H}$ & $\begin{array}{l}\text { Effect } \\
\text { Score:1 }\end{array}$ & $\begin{array}{l}\text { Benign } \\
\text { Score: } 0.001\end{array}$ & $\begin{array}{l}\text { Disease } \\
\text { P: } 0.658\end{array}$ & $\begin{array}{l}\text { Disease } \\
\text { P: } 0.589\end{array}$ & $\begin{array}{l}\text { Benign } \\
23.2\end{array}$ & $\begin{array}{l}\text { Neutral } \\
\text { Score: }-0.786\end{array}$ & Possibly damaging \\
\hline V153I & $\begin{array}{l}\text { Neutral } \\
\text { Score: } 74\end{array}$ & $\begin{array}{l}\text { Benign } \\
\text { Score: } 0.003\end{array}$ & $\begin{array}{l}\text { Neutral } \\
\text { P: } 0.149\end{array}$ & $\begin{array}{l}\text { Neutral } \\
\text { P: } 0.083\end{array}$ & $\begin{array}{l}\text { Benign } \\
23.4\end{array}$ & $\begin{array}{l}\text { Neutral } \\
\text { Score: }-0.205\end{array}$ & Possibly damaging \\
\hline
\end{tabular}

(A)

tr|Q7ZYG3 |Q7ZYG3_XENLA
SP|QO0977|CXB2_MOUSE
SP |P21994|CXB2_RAT
SP|P46691|CXB2_SHEEP
SP|Q8MIT8|CXB2_MACMU
SP|P29033|CXB2_HUMAN
SP|Q8MHWS | CXB2_GORGO
tr|J9NXRS|J9NXRS_CANLF

(B)

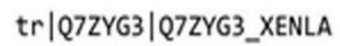
SP|Q00977|CXB2_MOUSE SP|P21994|CXB2_RAT SP|P46691|CXB2_SHEEP SP|Q8MIT8|CXB2_MACMU SP|P29033|CXB2_HUMAN SP|Q8MHW5 |CXB2_GORGO tr|J9NXR5|J9NXR5_CANLF
B..WT

MDWGTLYEVIGGVNRHSTSIGKIWLSVLFIFRIMILVVAAESWGDEQSDFTCNTLQPGC MOWGTLQSILGGVNKHSTSIGKIWLTVLFIFRIMILVWAKEWWGDEADFVCNTLQPGC MOWGTLQSILGGVNKHSTSIGKIWLTVLFIFRIMILWAAKEWWDEQADFVCNTLQPGC MDWSALQTILGGVNKHSTSIGKIWLTVLFIFRIMILVVAAKEWWGDEQADFVCNTLQPGC MOWGALQTILGGVNKYSTSIGKIWLTVLFIFRIMILVVAAKEWWGDEQADFVCNTLQPGC MOWGTLQTILGGVNKHSTSIGKIWLTVLFIFRIMILVVAAKEWWDEQADFVCNTLQPGC MDWGTLQTILGGVNKHSTSIGKIWLTVLFIFRIMILVAAKEWGDEQADFVCNTLQPGC MOWSTLQTILGGVNKHSTSIGKIWLTVLFIFRIMILWAAKEWWDEQADFVCNTLQPGC $* * *,:^{*}::^{* * * *}::^{* * * * * * * * *}: * * * * * * * * * * * * * *,,^{* * * * * *}: * *, * * * * * * * *$
B P.RI27H
B. R1531
LKQRKVRIRGTLWWTYTTSILFRVLFEAAFMYLFYYLYSGFHMPRLVQCNNWPCPNVVDC IKTQKVRIEGSLWWTYTTSIFFRVIFEAVFMYVFYIMYNGFFMQRLVKCNAWPCPNTVDC IKTQKVRIEGSLWWTYTTSIFFRVIFEAVFMYVFYIMYNGFFMQRLVKCNAWPCPNTVDC IKNQKVRIEGSLWWTYTGSIFFRVIFEAAFMYVFYVMYDGFAMQRLVKCNAWPCPNTVDC IKTQKVRIEGSLWWTYTSSIFFRWFEAAFMYVFYVMYDGFSMQRLVKCNAWPCPNTVDC IKTQKVRIEGSLWWTYTSSIFFRVIFEAAFMYVFYVMYDGFSMQRLVKCNAWPCPNTVDC IKTQKVRIEGSLWWTYTSSIFFRVIFEAAFMYVFYVMYDGFSMQRLVKCNAWPCPNTVDC IKSQKVRIEGSLWWTYTSSIFFRVIFEAVFMYVFYVMYDGFSMQRLVKCNAWPCPNTVDC $:^{*}:^{* * * *},{ }^{*}: * * * * * * * *: * * *: * * *, 0^{* * *}:^{* *}:^{*}, 0^{* * * * * *}:^{* * * * * * *}, * * *$

Figure 2. Multiple sequence alignment of connexin 26 protein (A). arrow showing I33T residue conservation (B). first arrow (from left to right) showing the $\mathrm{R} 127 \mathrm{H}$, and second arrow showing the $\mathrm{V} 153 \mathrm{I}$ residue conservation.
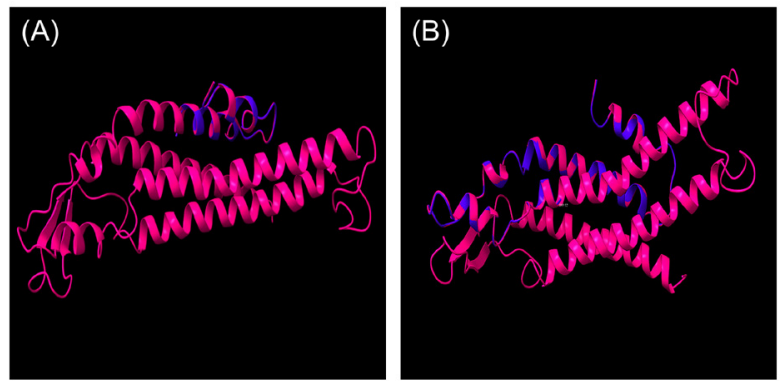

Figure 3. Connexin 26, the 3D structure of the protein. (A), Superimposed connexin 26 protein model with wildtype and truncated protein (Blue- W24 truncated protein, Red- wild type protein); (B), superimposed protein structure W77 truncated and wild type protein ( Blue- W77 truncated protein, Red- wild type).

\section{Discussion}

An overview of the mutation spectrum of the connexin 26 gene of 368 cohorts with hearing loss is presented in this study. A worldwide study on the GJB2 gene shows that it is a frequently mutated gene compared to other deafness related gene loci (11). W24X (25\%), R127H (14.9\%), W77X (5.2\%) mutation frequencies were found to be higher in our study. 2 missense variations were also recorded in our cohorts viz, I33T (4.9\%), and V153I (4.9\%). In East Asian lineages, c.235delC is the major mutation that causes hearing loss (12). European and African ancestors recorded the $35 \mathrm{delG}$ and C.167delT mutations as a causative factor for NSHL (11). GJB2 mutations were found in $\sim 11.5 \%$ of deaf families of south Iran and c.35delC was the common mutation identified (13). In our study, we didn't find $35 \mathrm{delG}$ and C.167delT mutations. Few studies done in India show $35 \mathrm{delG}$ and c.71G $>\mathrm{A}(\mathrm{W} 24 \mathrm{X})$ as major deafness causing gene mutations $(6,14)$. Mutations recorded in the $G J B 2$ (exon 2) coding region (W24X, W77X), described in this study, have been found previously in a few subjects from Indian subcontinents, including India (5). In southern Europe and the United States, congenital deaf cases have biallelic GJB2 mutations (between 30$35 \%)(15-17)$. A study on the Chinese Hans population has also recorded $25.65 \%$ of Hearing-Impaired patients had biallelic mutations in the GJB2 gene (18). Whereas only $10-20 \%$ of congenital deaf cohorts in India have biallelic GJB2 mutations. Therefore, we predict that, there may be additional deafness causing genes that are common in India, other than those already found. We 
used the Clustal Omega multiple sequence alignment tool, to analyze evolutionary conservation in each amino acid position. It is observed that $\mathrm{R} 127 \mathrm{H}$, and $\mathrm{I} 33 \mathrm{~T}$ polymorphisms are highly conserved, and polymorphism V153I is semi conserved (Figure 3). Two different studies transfecting the $\mathrm{R} 127 \mathrm{H}$ polymorphism to Hela cells have been conducted. In the first study the R127H mutation acts like a normal connexon 26 protein (19). In the second study, it forms the gap junction but there is a reduction in the activity of the gap junction $(5,20)$. Bioinformatics analysis on mutations observed in our study also revealed that the $\mathrm{R} 127 \mathrm{H}$ polymorphism is non-pathogenic (Table 3 ). In other Indian populations the $\mathrm{R} 127 \mathrm{H}$ mutation strongly suggests that, this is not a causative polymorphism for hearing loss even though its recorded at high frequency. W24X mutation in our cohort shows a heterozygous condition in six subjects with hearing loss and also R127H and V153I polymorphisms were heterozygous in 2 samples. The cause of deafness in those subjects could be because of many factors. The major possibility may be the digenic origin, which is an implication of another connexin gene (GJB3 or GJB6). We have restricted our study to a single gene because of the major involvement of the GJB2 gene in hearing loss.

Over 200 or more GJB2 gene mutations are recorded on the home page of connexin (http://davinci.crg.es/ deafness), so it's necessary to sequence the complete coding region of this gene. The frequency of the pathogenic mutation (W24X) in the GJB2 gene is high in our study population. From this study we can suggest that identifying this mutation in new-borns definitely helps in the early diagnosis of hearing loss. So, implementation of strategies to overcome the disability at an early stage is possible. Using sequencing techniques or restriction analysis, assay mutations can be easily identified. In a country like India, there is a high level of consanguinity and ethnicity and as such these techniques can be easily included, which also help in genetic counselling. This will be beneficial in the early rehabilitation of congenital hearing-impaired children. There is a need for expanding screening in other deafness genes to further resolve GJB2 mutations. This is the first study to see the effect of genetic variation in deafness in the north Karnataka population. In north Karnataka, out of 12 districts only 4 districts have been included for the genetic analysis of the single targeted gene (GJB2) in hearing impaired children was the major limitation of our study.

\section{Acknowledgements}

We thank all the patients and their families for cooperation during the study. The authors also thank all the doctors of the ENT department who participated and helped throughout the study. We thank Karnataka Institute for DNA Research, Dharwad and BLDE (Deemed to be university), and Vijayapura for their constant support throughout the research. We also take this opportunity to express our special thanks to Dr Nandish Kadkol for his help during the study.

Funding: This study was supported by Grants-in-Aid for research from Department of Higher Education, Government of Karnataka (Department of Higher Education, ED 15 UKV 2018, Bangalore, Date 12/13/2018).

Conflict of Interest: The authors have no conflicts of interest to disclose.

\section{References}

1. Kelsell DP, Dunlop J, Stevens HP, Lench NJ, Liang JN, Parry G, Mueller RF, Leigh IM. Connexin 26 mutations in hereditary non-syndromic sensorineural deafness. Nature. 1997; 387:80-83.

2. Banjara H, Mungutwar V, Swarnkar N, Patra P. Detection of Connexion 26 GENE (GJB2) Mutations in Cases of Congenital Non Syndromic Deafness. Indian J Otolaryngol Head Neck Surg. 2016; 68:248-253.

3. Pavithra A, Chandru J, Jeffrey JM, Karthikeyen NP, Srisailapathy CRS. Rare compound heterozygosity involving dominant and recessive mutations of GJB2 gene in an assortative mating hearing impaired Indian family. Eur Arch Otorhinolaryngol. 2017; 274:119-125.

4. Duman D, Tekin M. Autosomal recessive nonsyndromic deafness genes: A review. Front Biosci (Landmark Ed). 2012; 17:2213-2236.

5. Ramshankar M, Girirajan S, Dagan O, Shankar HMR, Jalvi R, Rangasayee R, Avraham KB, Anand A. Contribution of connexin26 (GJB2) mutations and founder effcet to non-syndromic hearing loss in India. J Med Genet. 2003; 40:e68.

6. Ghosh M, Vijaya R, Kabra M. Genetics of deafness in India. Indian J Pediatr. 2004; 71:531-533.

7. Mani RS, Ganapathy A, Jalvi R, Srikumari Srisailapathy CR, Malhotra V, Chadha S, Agarwal A, Ramesh A, Rangasayee RR, Anand A. Functional consequences of novel connexin 26 mutations associated with hereditary hearing loss. Eur J Hum Genet. 2009; 17:502-509.

8. Kemperman MH, Hoefsloot LH, Cremers CWRJ. Hearing loss and connexin 26. J R Soc Med. 2002; 95:171-177.

9. Yilmaz A. Bioinformatic analysis of GJB2 gene missense mutations. Cell Biochem Biophys. 2015; 71:1623-1642.

10. Chenna R, Sugawara H, Koike T, Lopez R, Gibson TJ, Higgins DG, Thompson JD. Multiple sequence alignment with the Clustal series of programs. Nucleic Acids Res. 2003; 31:3497-3500.

11. Tariq H, Zaigham K, Kousar S, Azhar A. Genetic contribution of GJB2 gene to hearing impairment in Pakistan. Advancements in Life Sciences. 2019; 7:38-43.

12. Kudo T, Ikeda K, Kure S, Matsubara Y, Oshima T, Watanabe KI, Kawase T, Narisawa K, Takasaka T. Novel mutations in the connexin 26 gene (GJB2) responsible for childhood deafness in the Japanese population. Am J Med Genet. 2000; 90:141-145.

13. Koohiyan M, Azadegan-Dehkordi F, Koohian F, Hashemzadeh-Chaleshtori M. Genetics of hearing loss in north Iran population: An update of spectrum and frequency of GJB2 mutations. J Audiol Otol. 2019; 23:175-180. 
14. Mishra S, Pandey H, Srivastava P, Mandal K, Phadke SR. Connexin 26 (GJB2) mutations associated with nonsyndromic hearing loss (NSHL). Indian J Pediatr. 2018; 85:1061-1066.

15. Lench N, Houseman M, Newton V, Van Camp G, Mueller R. Connexin-26 mutations in sporadic non-syndromal sensorineural deafness. Lancet. 1998; 351:415.

16. Denoyelle F, Weil D, Maw MA, et al. Prelingual deafness: High prevalence of a $30 \mathrm{delG}$ mutation in the connexin 26 gene. Hum Mol Genet. 1997; 6:2173-2177.

17. Kelley PM, Harris DJ, Comer BC, Askew JW, Fowler T, Smith SD, Kimberling WJ. Novel mutations in the connexin 26 gene (GJB2) that cause autosomal recessive (DFNB1) hearing loss. Am J Hum Genet. 1998; 62:792799.

18. Yu X, Lin Y, Xu J, Che T, Li L, Yang T, Wu H. Molecular epidemiology of Chinese Han deaf patients with bi-allelic and mono-allelic GJB2 mutations. Orphanet J Rare Dis. 2020; $15: 29$.

19. Thönnissen E, Rabionet R, Arbonès ML, Estivill X,
Willecke K, Ott T. Human connexin26 (GJB2) deafness mutations affect the function of gap junction channels at different levels of protein expresion. Hum Genet. 2002; 111:190-197.

20. D'Andrea P, Veronesi V, Bicego M, Melchionda S, Zelante L, Di Iorio E, Bruzzone R, Gasparini P. Hearing loss: Frequency and functional studies of the most common connexin26 alleles. Biochem Biophys Res Commun. 2002; 296:685-691.

Received December 16, 2020; Revised January 15, 2021; Accepted January 27, 2021.

*Address correspondence to:

Pramod B Gai, Karnataka Institute for DNA Research Dharwad 580003, India.

E-mail: pramodbgai@gmail.com

Released online in J-STAGE as advance publication February 5, 2021. 